\title{
Use of Discourse Markers in the Composition Writings of Arab EFL Learners
}

\author{
Abdulhafeed Saif Modhish \\ Department of English, Faculty of Education, Taiz University, Yemen \\ E-mail: abdulhafeed70@gmail.com
}

Received: March 8, 2012

Accepted: April 6, 2012

Published: May 1, 2012

doi:10.5539/elt.v5n5p56

URL: http://dx.doi.org/10.5539/elt.v5n5p56

\begin{abstract}
The purpose of this paper is to investigate the use of discourse markers that Yemeni EFL learners use in their composition writings. The research questions addressed in this paper are (1) what are the DMs that are frequently used by Yemeni EFL learners? , and (2) is there a direct relationship between the use of such markers and the writing quality of the learners in question? The 50 essays written by the study sample were analyzed following Fraser's (1999) taxonomy. The findings of the study reveal that the most frequently used discourse markers are the elaborative ones, followed by the inferential, contrastive, causative and topic relating markers. It is also shown that there is no strong positive correlation between learners' total number of discourse markers used and the writing quality of the participants. There is, however, a positive correlation between the topic relating markers and the writing quality of the learners. The paper concludes with some recommendations and suggestions that should inform EFL writing instruction in this part of the world and in other similar contexts.
\end{abstract}

Keywords: Discourse Markers, Text Coherence, Second Language Acquisition, Yemeni EFL learners

\section{Introduction}

In general, writing in L2 is viewed as a demanding task, and for L2 learners to be able to produce discourse that conforms to the norms of discourse created by their native counterparts, they need to be familiar with the various components of writing that would assist them to write effectively. Being able to produce grammatically correct sentences in L2 is undoubtedly important, but awareness of how discourse in L2 is created is also of great importance.

Given the fact that English has become the language of communication all over the globe, EFL learners need to write effectively so as to be able to cope with the challenges of their academic pursuits. Thus, awareness of the use and practicality of Discourse Markers (henceforth DMs) can immensely contribute to the overall quality of the discourse created by ESL/EFL learners. Rahimi (2011) rightly points out that DMs constitute an essential component of communicative competence. In other words, DMs help learners produce fluent and meaningful discourse in English. The following section is to give an idea about DMs and how they can be manipulated to create meaningful discourse in L2.

Schiffrin (1987, p.31) defines DMs as "sequentially dependent elements which bracket units of talk." Similarly, Carter (2007) defines the same as "intra-sentential and supra-sentential linguistic units which fulfill a largely non-propositional and connective function at the level of discourse, (p. 411)." Swan (2005), moreover, gave a more simplistic account of DMs saying:

Some words and expressions are used to show how discourse is constructed. They can show the connection between what a speaker is saying and what has already been said or what is going to be said; they can indicate what speakers think about what they are saying or what others have said.

This study is an investigation into the use of DMs in the composition writings of Yemeni EFL learners. The motivation behind initiating this kind of work stems from the fact that there is a dearth of research that is concerned with how DMs are actually utilized in the written discourse created by Arab EFL learners. Thus, this study is meant to fill this gap in research and it is hoped that it will yield some insight into this 'overlooked' though extremely important area of second language writing.

\section{Literature Review}

In the last two decades or so, a good deal of research has been devoted to the scrutiny and analysis of discourse 
markers. For instance, the influential work done by Halliday and Hasan (1976), Cohesion in English, immensely contributed to the emergence of studies and empirical research on discourse cohesion and coherence and this naturally led to the study of DMs as a new and promising area of enquiry. Similarly, the research initiated by Schiffrin (1987) and Fraser $(1990,1999)$ has resulted in numerous studies that gave descriptive and classificatory accounts of such linguistic elements and motivated other researchers to carry out qualitative and quantitative research on this very important area of second language writing. Fraser $(1999$, p.301) rightly pointed out that DMs have become a "growth industry in Linguistics..."

Research on DMs has attempted to find out answers as to what they are, what they mean and what functions they manifest. Depending on the theoretical background or framework under which these markers are analyzed and discussed, they have been given various labels. For instance, they were referred to as sentence connectives (Halliday and Hasan, 1976), discourse connectives (Blakemore, 1987), pragmatic markers (Fraser, 1999), just to mention a few. Examples of DMs are words such as well, y'know, actually, in fact, furthermore, because, but, and, etc.

As outlined above, the work initiated by Halliday and Hasan (1967), which mainly focused on discourse cohesion, was the stepping stone towards indulging into the multidimensional world of DMs. Naturally, this influential work has given rise to a great deal of research in the area of discourse coherence and cohesion and consequently led to the emergence of numerous studies that tackled DMs so as to find out about the role played by such linguistic items to create cohesively and coherently meaningful discourse. Halliday \& Hasan have given certain cohesive devices that are used to achieve coherence in texts and are outlined below:

- reference

- ellipsis

- substitution

- lexical cohesion

- conjunction

Acknowledging the fundamental role played by discourse markers in achieving discourse coherence, Taboada (2006, p. 7) pointed out that the most frequently studied markers "signaling coherence relations are discourse markers." Evidently the pioneer work of Schiffrin (1987) was, in fact, a serious attempt towards an in-depth exploration of the various DMs that are used in both oral and written discourse and how they significantly contribute to discourse coherence, though she gave more emphasis to DMs that are commonly used in oral interactions. She analyzed in detail expressions such as and, because, but, I mean, now, oh, or, so, then, well, and $y^{\prime} k n o w$ as they occur in unstructured interview conversations. Schiffrin (1987) (quoted in Buyukkarci \& Gene, 2009) has given a number of characteristics as to what constitutes a discourse marker and are given below:

- It has to be syntactically detachable from the sentence

- It has to be commonly used in initial position of an utterance

- It has to be able to operate at both local and global levels of discourse

- It has to be able to operate on different planes of discourse

- It has to have a range of prosodic contours

In the same vein of research, Fraser (1993) argued that a discourse marker is not an integral part of the propositional meaning of a sentence as it is detachable and can even be deleted and this is unlikely to change the content meaning or the grammaticality of the sentence. Absence of DMs from discourse obviously does not change the grammaticality of sentences but "it does remove a powerful clue about what commitment the speaker makes regarding the relationship between the basic message conveyed by the present utterance and the prior discourse" (Fraser, 1993, p. 4).

As an extension to his earlier work, Fraser $(1996 ; 1999)$ approached DMs from a rather pragmatically-oriented perspective. That is, what DMs mean or the function they manifest, he argued, is to be negotiated by discourse interlocutors and context-related clues are instrumental to the interpretation of such markers. Such markers are liable to assume different functions depending on the context in which they occur. He asserts that DMs have core meaning and procedural meaning. Stressing the role of DMs in creating meaningful discourse, Muller (2005, p. 20) postulates that "there is a general agreement that discourse markers contribute to the pragmatic meaning of utterances and thus play an important role in the pragmatic competence of the speaker."

Since the current paper is mainly concerned with the use of DMs in written discourse, the following section is to be devoted to a brief discussion of some of the studies that have dealt with the use of DMs in the writings of nonnative 
speakers of English. Jin (2009), for example, conducted a study in which she explored the use of contrastive markers (CDMs) by Japanese and Chinese learners of English. Results of this study showed that the use of CDMs by the study sample was rather restricted to those familiar to them. Some of the functions of but as used by the Chinese and Japanese learners were triggered by their word-for-word translation from their L1 to English. Jin attributed this restricted use of CDMs to the fact that the learners are cautious of making mistakes when using some unfamiliar CDMs. The author attributed the limited use of DMs to the fact that the explanation of CDMs by writing instructors is inadequate or inappropriate.

Furthermore, Jalilifar's (2008) study investigated DMs in descriptive compositions of 90 Iranian EFL learners. The findings of this particular study showed that students used DMs with different degrees of occurrence. Elaborative markers were the most frequently used, followed by inferential, contrastive, causative, and topic relating markers. It also revealed that the number of well functioned DMs positively contributed to the writing quality of learners' compositions. Jalilifar postulated that the learners who were better able to effectively and appropriately use DMs were more successful in producing more coherent compositions.

Likewise, Martinz (2004) investigated the use of DMs in the compositions of Spanish undergraduates. She found that the elaborative markers were the most frequently used, followed by contrastive markers. She ascertained that there was a positive relationship between the use of DMs and the writing quality of the learners. Put it differently, the greater the number of DMs that are used appropriately by the learners, the better the quality of their writings.

\section{Research Objective}

The present paper aims to look into the use of DMs in the composition writings of Yemeni EFL learners majoring in English at Taiz University (henceforth TU). It also aims to examine the relationship between the use of DMs and the writing quality of the learners in question. The paper will thus attempt to address the following questions: 1) what are the DMS that are frequently used by the Yemeni English majors in their essay writings? 2) To what extent is there a correlation between use of DMs and the writing quality of the compositions produced by the learners?

\section{Methodology}

\subsection{Participants}

The participants of this study are the students of level three that are enrolled in the four-year undergraduate program at TU, Yemen. They are assumed to be socio-linguistically homogeneous, and are between 22 and 23 years of age. It is worth pointing out that the learners in question have already done language courses such as Reading and Composition 1, 2, 3, and 4 in addition to four Spoken English courses and Grammar and Usage courses.

\subsection{Data Collection Procedure}

This study is based on the data collected from a randomly selected sample. 50 essays out of the 150 ones written by level three EFL learners were analyzed to find out about the frequency and nature of the DMs used by the learners. The participants of this study were given a writing task, that is, they were required to compose a three-paragraph essay on "the role technology plays in making life easier and more interesting." 50 essays written by these learners were subjected to thorough analysis and attention was focused on their use and manipulation of DMs so as to achieve a unified piece of writing at the essay level. With regard to writing quality, the 50 essays were rated by two EFL writing instructors on the basis of (grammar, content, style, punctuation and spelling).

The collected data were analyzed mainly quantitatively and qualitatively. To this end, statistical measures were utilized to present data statistically by means of frequency of occurrence of DMs, mean of occurrence and percentages. Besides, correlation between the total number of DMs employed by the learners and the writing quality of their compositions was conducted by means of Pearson's correlation device. In a word, SPSS, with its inbuilt features, was used to carry out such statistical analyses.

\section{Results and Discussion}

The compositions of the learners who participated in this study were looked into to find out about the kind of DMs they have used in their essay writings. The results showed that they have made use of elaborative, inferential, contrastive, causative, and topic relating markers. Apparently the learners extensively used elaborative DMs (204) and this is also reflected in the mean score shown in table 1 below. The overuse of elaborative markers might have been triggered by the nature of the writing task the learners got involved in, which is expository writing. The occurrence of the marker 'and' is evidently noticeable in the data and this particular DM is widely used in spoken as well as written Arabic, so the occurrence of this particular marker might have been triggered by the learners' reliance on their L1.

[Insert Table 1 here] 
[Insert Table 2 here]

Table 2 clearly shows that there is no strong positive correlation between the DMs utilized by the learners in their essays and the quality of their writing. And this can be due to certain factors that have to do with the fact that the learners' repertoire of DMs is rather limited and the study clearly revealed that their use of DMs is rather restricted. Moreover, they tended to make use of DMs that they are pretty sure of how to use them and would not take the risk of trying to use some of the unfamiliar ones. What is more, some learners are afraid of making mistakes so they feel reluctant to adventure with DMs that are unfamiliar to them. Another reason has to do with the fact that learners get obsessed with the grammaticality of the sentences they produce and the ideas that they want to spell out; as a consequence, very little room is left for DMs. Additionally, it seems that DMs are not given the due importance they deserve by writing instructors and EFL teachers in general.

Absence of rigorous EFL writing courses that adequately address all the components of writing as an independent skill eventually leads to poor EFL writers. To add insult to injury, learning English in such an acquisition-poor environment where real and authentic language input is rather scarce does not seem to alleviate the overall competence of the learners in the target language. Thus, one can come to the conclusion that DMs are not sufficiently tackled by the EFL program under discussions. Put differently, the teaching materials and methods still adhere to the approaches that solely focus on accuracy and pay little attention to the language components that enable learners to communicate effectively and appropriately in English.

The topic relating markers are, however, shown to be strongly positively correlated with the writing quality of the learners as shown in table 3 below, correlation is significant at 0.05 . This reveals that some of the learners who were able to correctly and appropriately use those topic relating markers wrote relatively better essays.

[Insert Table 3 here]

It is quite obvious that the use of DMs by the learners in question is rather restricted. The heavy reliance on the use of and and also as elaborative markers clearly indicates that the learners are not aware of the existence of the other elaborative markers or they are reluctant to use them due to fear of making errors. That is, they would prefer to use the ones they know for certain that they would use them correctly and appropriately. This phenomenon is referred to in the literature as avoidance which characterizes the linguistic behavior of some L2 learners.

The excerpts given below are obtained from the learners' essays and are intended to show how these particular EFL writers use DMs in their compositions:

The following excerpt is extracted from the essay produced by S5. It shows how learners heavily and exclusively rely on and and also as elaboration markers.

Most of people in this century especially in developed country using technology in everything in their life and we also using technology in the Arabic world this technology make our life easier and keep the people in touch with other, if we want to make a search about anything we can enter internet and get everything about it.

This rather long and wordy sentence reveals that the learner in question seems to be somehow oblivious to the world of DMs and is trying his utmost to spill out the ideas that he wants to convey to the reader. Further, this sentence shows that the linguistic competence of the learner is not mature enough to be able to produce grammatically correct sentences and this is beyond the scope of the present paper.

The excerpt to follow is extracted from the essay written by S18 and it shows how the learners heavily rely on the use of so as an inferential marker. Though there are many other inferential markers available to the learners, their use of such markers is restricted to so and this is again due either to the avoidance phenomenon or to the learners' unfamiliarity with the other inferential markers.

Another reason is that it is used in industry. So we can say that it replaced persons who work with much efforts. Machines work technically and produce full completely products. So technology serves us to get healthy and fast food.

Moreover, this extract shows that the composition produced by S16 is entirely void of discourse markers. Unawareness of the importance of the use of DMs causes learners to create sentences that are not coherently pieced together.

The internet is very important thing in our life. It makes the life easier than before. It makes communication very easy between the people. We can get about any information that we want. We can keep anything inside it in a secret way.

It is clear that the writing-related performance of the learners is rather poor and this is not only ascribed to their restricted use of discourse markers but also to the grammatically erroneous sentences that they have produced. 
Additionally, the poor quality of the essays can also be ascribed to the learners' tendency to produce rather long sentences. It is true that use of discourse markers makes learners' compositions more coherent but scarcity of DMs in learners' essays in addition to other inadequacies makes their compositions less coherent and rather fragmented. EFL Programs that are specifically designed to address all those writing related problems that Arab learners encounter are desperately needed to pinpoint those problems and to subsequently tackle them.

The findings of the present study are in line with the findings of the previously conducted research that the use of DMs by EFL learners is rather limited and this affects the quality of their compositions (Rahimi, 2011; Jin, 2009; Jalilifar, 2008; Martinz; 2004). This study, however, shows that the use of DMs is restricted to those familiar to the learners and these DMs did not seem to have a positive impact on the quality of learners' writings. The use of topic relating markers did seem to positively affect the quality of the writings of some of the participants. In other words, appropriate use of topic relating markers by some participants of this study enabled them to create well-written essays.

\section{Conclusions and Recommendations}

The results of this study have shown that the learners have overused the elaborative markers followed by inferential, contrastive, causative, and topic-relating markers. The use of DMs by the learners is rather restricted and this indicates that the learners have extensively used those markers such as and, also, so, but; and these are the markers that might have kept on recurring in the teaching materials and in the classroom instruction carried out by their writing instructors. In addition, it was revealed that there is no positive correlation between the use of DMs and the writing quality of the learners' compositions. However, there is a correlation between the learners' use of topic relating markers and the quality of their compositions. Student writers who have correctly and appropriately used topic relating markers tended to produce relatively better essays.

The quality of the essays written by the learners can be viewed as poor and this reveals that writing is not sufficiently dealt with by many EFL programs in the Arab world. To clarify more, the restricted use of DMs on the part of the learners indicates that such an important component of any writing course is apparently neglected. Thus, for learners to be able to appropriately use such markers, adequate exposure to such linguistic items is very crucial. Put differently, such items, discourse markers, need to be tackled explicitly and implicitly by writing instructors. Accessibility of such markers to the learners will enable them to produce coherent and cohesive essays. Consequently, the explicit and implicit teaching of DMs should be an integral part of writing courses offered to EFL learners.

It is advisable that the EFL programs in the Arab world and in the other similar contexts treat writing as a separate skill and not to be looked at as a secondary skill that is not given the attention it deserves. What is more, EFL learners should be encouraged by writing instructors to adventure with the language and not to be unnecessarily cautious of making errors as this might lead learners to be rather inhibited. Furthermore, it should be emphasized once again that DMs ought to be tackled inductively and deductively by English language teachers in general and EFL writing instructors in particular. Providing learners with adequate exposure in L2 will certainly enable learners to pay attention to these linguistic items and become aware of the facilitating role they play in making their texts more coherent and cohesive.

A more detailed study that should look into the nature of DMs in Arabic would provide EFL instructors in the Arab world with some important clues and insight into how such linguistic items are used. This would help design teaching materials that would tackle the problems encountered by Arab EFL learners and to draw their attention to the importance of DMs in enabling them to produce coherent and cohesive compositions. Furthermore, a comparative study of DMs in English and Arabic would certainly prove fruitful for the teachers of writing skill in this part of the world. It is hoped that this kind of research would add another building block to the research work concerned with the difficulties encountered by Arab EFL learners when they attempt to compose in English.

\section{References}

Blakemore, D. (1987). Semantic Constraints on Relevance. Oxford: Blackwell.

Buyukkarci, K., \& Gene, B. (2009). Discourse Markers: The case of and in Speech of Turkish Speakers of English. The Linguistics Journal, 4, 40-50.

Carter, R., \& Fung, L. (2007). Discourse Markers and Spoken English: Native and Learner Use in Pedagogic Settings. Applied Linguistics, 28, 410-439. http://dx.doi.org/10.1093/applin/amm030

Fraser, B. (1990). An approach to discourse markers. Journal of Pragmatics, 14, 383-395. http://dx.doi.org/10.1016/0378-2166(90)90096-V 
Fraser, B. (1993). Discourse Markers Across Language. Pragmatics and Language Learning, 4, 3-18.

Fraser, B. (1999). What are discourse markers? Journal of Pragmatics, 31, 931-952.

Halliday, M., \& Hasan, R. (1976). Cohesion in English. London: Longman.

Jalilifar, A. (2008). Discourse Markers in Composition Writings: The case of Iranian learners of English as a foreign language. English Language Teaching, 1, 114-122. http://dx.doi.org/10.1016/S0378-2166(98)00101-5

Martinez, A. C. L. (2002). The use of Discourse Markers in E.F.L. learners' Writing. Revista Alicantina de Estudios Ingleses, 15, 123-132.

Muller, S. (2005). Discourse Markers in the native and Non-native English Discourse. John Benjamins: Philadelphia.

Rahimi, M. (2011). Discourse Markers in Argumentative and Expository Writing of Iranian EFL Learners. World Journal of English Language, 1(2), 68-78. http://dx.doi.org/10.5430/wjel.v1n2p68

Schiffrin, D. (1987). Discourse Markers. Cambridge: Cambridge University Press.

Swan, M. (2005). Practical English Usage. Oxford: Oxford University Press.

Taboada, M. (2006). Discourse Markers as Signals (or Not) of Rhetorical Relations. Journal of Pragmatics, 1-31.

Ying, S. (2009). Remarks on Contrastive Discourse Markers (CDMs) in Writings by non-native English learners. US-China Foreign Language, 7, 40-46.

Table 1. Shows frequencies of the DMs

\begin{tabular}{|l|r|r|r|}
\hline & $\mathrm{N}$ & Sum & \multicolumn{1}{|c|}{ Mean } \\
\hline elaborate & 50 & 204.00 & 4.0800 \\
inferential & 50 & 70.00 & 1.4000 \\
contrastive & 50 & 64.00 & 1.2800 \\
causative & 50 & 37.00 & .7400 \\
Topic relating & 50 & 9.00 & .1800 \\
\hline
\end{tabular}

Table 2. Shows no correlation between writing quality and use of DMs

\begin{tabular}{|l|r|l|l|}
\hline & & \multicolumn{1}{|c|}{ TOTAL } & Writing quality \\
\hline TOTAL & Pearson Correlation & 1 & .113 \\
& Sig. (2 tailed) & & .434 \\
& $\mathrm{~N}$ & 50 & 50 \\
\hline Writing & Pearson Correlation & .113 & 1 \\
quality & Sig. (2 tailed) & .434 & \\
& $\mathrm{~N}$ & 50 & 50 \\
\hline
\end{tabular}

Table 3. Shows correlation between writing quality and topic relating DMs

\begin{tabular}{|rr|l|l|}
\hline & & Writing quality & Topic relating \\
\hline Writing quality & Pearson Correlation & 1 & $.284^{*}$ \\
& Sig. (2 tailed) & & .045 \\
$\mathrm{~N}$ & 50 & 50 \\
\hline Topic relating & Pearson Correlation & $.284^{*}$ & 1 \\
& Sig. (2 tailed) & .045 & \\
$\mathrm{~N}$ & 50 & 50 \\
\hline
\end{tabular}

